\title{
O SUJEITO ECOLÓGICO: OBJETIVAÇÃO E CAPTURA DAS SUBJETIVIDADES NOS DISPOSITIVOS E ACONTECIMENTOS AMBIENTAIS
}

Adalberto Ferdnando Inocêncio ${ }^{1}$

Fabiana Aparecida de Carvalho ${ }^{2}$

Resumo: Recorre-se à analítica foucaultiana e pós-crítica para, neste ensaio, problematizar as discursividades e os dispositivos que atravessam o sujeito ecológico, compreendido como figura identitária fabricada por discursos ecológicos do Estado, do mercado e dos processos de objetivação/dominação das subjetividades. Criticam-se os processos de subjetivação desse sujeito mediante a noção de acontecimento discursivo na história, sobretudo, para se pensar a crise ambiental na contemporaneidade e os impedimentos para assumir éticas não hegemônicas e posturas ambientais diferenciadas das vigentes.

Palavras-chave: Acontecimento Discursivo; Crise Ambiental; Subjetivação.

Abstract: In this essay, Foucaultian analysis and post-criticism are used to problematize the discursivities and dispositif that permeate the ecological subject, understood as an identity figure manufactured by ecological discourses of the State, the market and the processes of objectification/domination of subjectivities. The subjectification processes of this subject are criticized through the notion of discursive event in history, in order to think about the environmental crisis in contemporary times and the impediments in assuming non-hegemonic ethics and environmental postures different from the current ones.

Keywords: Discursive Event; Environmental Crisis; Subjectivation.

1 Universidade Estadual de Maringá (UEM). E-mail: afinocencio88@gmail.com.

Link para o Lattes: http://lattes.cnpq.br/2512088867369823.

2 Universidade Estadual de Maringá (UEM). E-mail: facarvalho@uem.br.

Link para o Lattes: http://lattes.cnpq.br/5954623442549080. 


\section{Introdução}

Neste ensaio teórico, buscamos problematizar e debater certas prerrogativas e alguns efeitos nos entendimentos referenciados pela categoria sujeito ecológico, ou seja, o sujeito objeto dos discursos sobre Educação Ambiental e figura central na construção de uma noção de crise ecológica.

De acordo com a literatura ambiental, o sujeito ecológico pode ser definido como um modo de ser no mundo, relacionado com o estilo de vida ecologicamente orientado (CARVALHO, 2000; CARVALHO, 2016; MELO E SOUZA, 2014; INOCÊNCIO, 2019). Essa categoria, atravessada por aspectos da vida psíquica, social, cultural e individual, é internalizada por grupos sociais e por pessoas que se identificam com ideários ambientais e perfazem uma subjetividade ecológica produtora de representações, de narrativas e de projetos identitários voltados, por exemplo, à Educação Ambiental e à mudança de atitudes e valores em relação aos diferentes ambientes e à vida social.

Em nosso entendimento, entretanto, a imputação dessa categoria/subjetividade configura-se como um acontecimento discursivo contemporâneo cujo processo de fabricação iniciou-se com os movimentos sociais de inclinação ambientalista, tendo continuidade com as diversas formas de sedução identitária incitadas pelo mercado econômico, pelo consumo de proposições e discursos ecológicos e pelas representações culturais inauguradoras de modos de ser no mundo considerados adequados à vida ecológica, por exemplo, a criação de táticas de vigilância das condutas ditas ambientais.

Para sustentar nosso argumento e problematizar a fulguração desse sujeito como um acontecimento na história, algumas teorizações de Michel Foucault e de autores de vertente pós-crítica - preocupados com os efeitos dos discursos e com a problematização de meta-categorias instituídas pela linguagem e em representações culturais - são acionadas como uma caixa de ferramentas analíticas não apriorística, ou seja, importa-nos não uma análise acerca da importância do sujeito de uma ecologia, mas algumas discursividades conformadoras das verdades dos sujeitos ambientais.

Para que pensamentos e verdades sejam instituídos, as palavras e as coisas precisam ser criadas junto às condições discursivas e não discursivas que Ihes atribuem legitimidade em uma rede de saberes e poderes (FOUCAULT, 2013a). Dito de outra forma, o discurso pode ser lido como acontecimento e os enunciados produzidos relacionam-se com circunstâncias de ordem econômica, social, política, ambiental etc. "Nesse contexto, em vez de uma figura propriamente dita da ecologia, o sujeito ecológico é uma invenção discursiva que nem sempre esteve no mundo, pronta, acabada, atuante em causas e ações ou militando ecologicamente.

Preocupamo-nos em construir um olhar para a materialidade histórica no que concerne à importância dada aos discursos que perfazem o sujeito ecologicamente correto, pois os significados atribuídos a esse ethos são 
enunciados e produzidos em práticas sociais que se entrelaçam, por exemplo, na consciência ambiental forjada nas práticas de Educação Ambiental, em desdobramentos sociais e nas táticas de ecogovernamentalidade (INOCÊNCIO; SALVI, 2017; INOCÊNCIO, 2019).

Vale dizer que Foucault, durante sua vida, alertou que seu empenho era o de elaborar uma história dos diferentes modos pelos quais as pessoas são constituídas como sujeitos (DREYFUS; RABINOW, 2013). Essa afirmação explicita o direcionamento adotado no ensaio: a compreensão de sujeito - um conceito explorado por inúmeras áreas do conhecimento vinculadas às Ciências Humanas e às questões ambientais.

Sob a inspiração da analítica foucaultiana, o sujeito ecológico pode ser concebido como um acontecimento discursivo recente na história (FOUCAULT, 2007). Ele é, portanto, produto de relações de saber e poder, ou seja, de bases e dispositivos sustentados por elementos em circunstâncias que permitem a criação e a dispersão dos acontecimentos ecológicos, como também o aparecimento, a condição de existência ou mesmo o desaparecimento desse próprio sujeito efeito ecológico.

Diferentemente dos postulados filosóficos sobre a materialidade e a alma humana, Foucault (2007) argumentou que somente com o advento das Ciências Humanas na modernidade pôde-se pensar na figura do homem como um objeto de estudo de uma ciência. Com base nessa premissa, advertimos que somente com o advento da crise ambiental, foi possível pensar na existência de um sujeito efeito/dominado por essa mesma crise e responsável por práticas educativas ou por práticas e condutas de conservação e ou preservação ${ }^{3}$ dos ambientes naturais, modificados e construídos.

A partir desse alinhamento, abre-se um espectro de formas e forças capazes de delinear enredamentos e discursos - o dito e o não dito - produtores de diversos tipos de sujeito histórico. Desse modo, em vez de empregar a expressão "existiram sujeitos ecológicos" ao longo dos tempos, preferimos a expressão "foram fabricados sujeitos ecológicos", a fim de visibilizar as contingências, as vontades, as necessidades e as características de um dado tempo-espaço social na subjetivação do ser ambientalmente correto. Sob esse prisma, aludimos, pois, aos modos de criação/fabricação de sujeitos que atravessam uma materialidade ambiental na história bem mais próxima das "formas de objetivação" (FOUCAULT, 2007).

A compreensão dessas formas requer, por sua vez, assumir que o sujeito não é a causa, mas, sim, o efeito de discursos, podendo ser atravessado e performatizado (BUTLER, 2003) por técnicas e práticas de determinadas épocas ou grupos socioculturais, em contraposição, por exemplo, à compreensão kantiana postuladora do sujeito como um self ou eu primordial. Mesmo que os corpos e os sujeitos estejam em negociação com tecnologias de dominação

\footnotetext{
${ }^{3}$ Neste ensaio, não optamos pelas digressões teóricas e críticas acerca dos conceitos e dos movimentos de conservação e preservação dos recursos ambientais.
}

Revbea, São Paulo, V.16, № 5: 94-114, 2021. 
diversas e sejam expropriados, ao se pensar na economia e na produtividade, eles não podem ser compreendidos como simples objetos sem vontade, mas, sim, como efeitos discursivos em constante negociação e como construções históricas.

Embora Foucault não tenha se debruçado especificamente sobre o estudo da fabricação do sujeito dito ecológico, ele se desdobrou para explicar três formas distintas de objetivação. De acordo com Benites (2015), na primeira objetivação, o sujeito se (re)conhece pelo viés de uma ciência a situá-lo como objeto de estudo, cujo objetivo é ensejá-lo como um corpo biológico dócil e econômico, capaz de oferecer sua força produtiva ao sistema; a segunda forma tem por finalidade principal esquadrinhar esse sujeito conforme segregações sociais, por exemplo, a separação de loucos, prisioneiros e demais corpos desinteressantes para o funcionamento dos Estados-Nação; e, finalmente, a terceira forma de objetificação entende o sujeito como um status de conhecimento de si, isto é, como uma figura que emerge de modos pelos quais as pessoas dão a si mesmas o status de sujeito.

Embora seja fabricado por todas essas modalidades objetificadoras (a ciência ecológica situando-nos como corpos zeladores dos ambientes ou corpos consumidores conscientes; a separação de sujeitos ecológicos e não ecológicos; - modo como performamos nossas identidades ambientais e atuamos ecologicamente), o sujeito ecológico é discutido neste ensaio pelos efeitos decorrentes da terceira via de objetivação, isto é, conhecer-se e ver-se como protagonista das causas ecológicas e adequado ao sistema social vigente, uma vez que ele é produto histórico dos saberes e poderes provenientes de movimentos sociais parcialmente capturados pelas investidas econômicas de mercado e de consumo que afetaram ou consolidaram, ao longo do tempo, as chamadas políticas e movimentos ambientalistas.

Essa objetivação, em nosso entendimento, não acontece separadamente das distintas formas históricas de organização social, de modo que um mesmo sujeito pode estar atravessado por todas as outras no decorrer de sua vida. Em outro sentido, pode-se dizer que as formas de objetivação compõem as chamadas técnicas de dominação (FOUCAULT, 2014a) ligadas a modos de ser e estar no mundo, produtivamente ensejados pelas instâncias exteriores ao sujeito, dentre elas: o Estado, o mercado, a igreja, a escola etc. As técnicas de dominação, portanto, objetivam um lugar para o sujeito, situando-o em posições corroboradoras dos mecanismos de dominação ${ }^{4}$ social e via técnicas de normatização/padronização das condutas pessoais e populacionais.

\footnotetext{
${ }^{4}$ Os mecanismos de dominação social, por não serem naturais, mas socialmente disputados, não têm totalidade em sua eficácia, havendo, antes, um combate incessante para firmar suas estratégias de dominação. Isso acontece porque as tecnologias de dominação não são as únicas a criar formas de relações. As técnicas de si, conforme evidenciam as últimas discussões foucaultianas, contribuem na construção de mecanismos mais libertos e inventivos de ser e estar no mundo, uma vez que são os próprios sujeitos as instâncias de sua produção. A discussão presente neste ensaio não ignora as técnicas de si, que são amplas e criativas no tecido
} 
Melo e Souza (2014) advertem que a adoção do constructo sujeito ecológico está vinculada às possibilidades de atuações humanistas, no entanto o termo congrega ambiguidades inerentes a certas orientações discursivas, dentre as quais, o próprio ideário humanista universal. Para esquadrinhar as contradições vale, conforme defende a autora, sempre perguntar qual sujeito, qual ecologia, qual sujeito ecológico e quais bases ideológicas entram na produção ou na objetificação das pessoas. Para tal, é necessária a adoção de uma problematização das questões vinculadas aos limites e às possibilidades desse conceito sujeito ecológico, colocando em evidência as contradições discursivas, as lógicas de subjetivação, as posições ecológicas em relação a algo, alguém ou contexto específico, principalmente quando o uso da expressão sujeito ecológico se adensa na contemporaneidade. E mais: trata-se de não dissociar o sujeito das políticas de identidade nas implicações políticas e relacionais com o mundo vivido e com os desdobramentos ambientais, principalmente, no contexto brasileiro (MELO; SOUZA, 2014).

Partindo das premissas situadas nesta introdução e dessa relação ecológica/ambiental fabricante dos sujeitos e dos processos identitários ambientais, nossa incursão teórico-analítica indaga e discute esse sujeito ecológico vislumbrado na atualidade, como se estabelecem as formas de dominação por meio da sujeição às discursividades ambientais, e problematiza a construção de identidades ecológicas fixadas por e nas instâncias produtoras das condições de existência do sujeito ecológico. Pari passu, pensamos a figura identitária desse sujeito como acontecimento na história, como acontecimento discursivo imerso em contradições nem sempre tão evidentes, a exemplo da contradição presente no sujeito ecológico policialesco. Nosso intento, portanto, é o de colocar em evidência a relação desse sujeito ecológico com a fabricada discursividade de crise ambiental.

\section{A subjetivação e o sujeito ecológico}

$\mathrm{Na}$ perspectiva foucaultiana, as noções de sujeito e subjetividade só fazem sentido à luz dos estudos das tecnologias de sujeição e dos múltiplos efeitos que elas produzem nos discursos em nossas relações com o meio ambiente. Foucault, ao preconizar as diferentes maneiras pelas quais as pessoas conhecem a si, distinguiu as técnicas/tecnologias modeladoras de subjetividades das experiências de mundo e das experiências de si que determinam, entre outras condições, as ações, os modos de ser e estar em sociedade e de se estabelecer relações coletivas e pessoais. Essas seriam: técnicas referentes aos modos de dominações que avassalaram o mundo e, em especial, o Brasil nas últimas décadas. 
1. as técnicas de produção por meio das quais nós podemos produzir, transformar e manipular objetos; 2. as técnicas de sistemas de signos, que permitem a utilização dos signos, dos sentidos, dos símbolos ou da significação; 3. as técnicas de poder, que determinam a conduta dos indivíduos, os submetem a alguns fins ou à dominação, objetivam o sujeito; 4. as técnicas de si, que permitem aos indivíduos efetuar, sozinhos ou com a ajuda de outros, certo número de operações sobre seu corpo e sua alma, seus pensamentos, suas condutas, seu modo de ser [...] (FOUCAULT, 2014a, p. 266 - grifos nossos).

Raramente, tais técnicas funcionam separadamente, apesar de estarem sempre associadas a diferentes modos de dominação. Ao compreendê-las, podemos pensar em quais articulações desenvolvemos com o mundo e conosco, sendo também possível falar em práticas de subjetivação ou em construção de subjetividades, em vez de, simplesmente, adotar a noção estanque de sujeito, cunhada na modernidade. Tal entendimento não desconsidera a importância das perspectivas que tratam do sujeito nas vertentes das identidades, principalmente em âmbitos que necessitam das pautas identitárias para dar conta de certas problemáticas sociais como o campo das políticas públicas. O que anunciamos, ao deslocar o papel das tecnologias na construção de subjetivação, subjetividades e identidades, é que o sujeito não permanece o mesmo em cada momento histórico (DREYFUS; RABINOW, 2013) ou tem uma única relação ocupante em um dado grupo social; o sujeito e a noção dessa categoria, portanto, estão sempre em trânsito.

Todavia, o reconhecimento da figura do sujeito como um discurso pronto, acabado e desconectado da história centraliza poderes e enrijece os atravessamentos de outras subjetividades, principalmente, aquelas que visibilizariam relações ecológicas não hegemônicas e não estruturadas por grandes corporações e aquelas que favorecem a modificação de quem somos em um dado momento. Para Rolnik (2018), a experiência estabelecida com o mundo é muito mais ampla do que aquilo que experimentamos na forma desse sujeito fechado, produzido, cuja experiência, neste caso, a ambiental, é programada; ao contrário, a experiência é sempre da ordem dos atravessamentos, dos fluxos e das intensidades.

Junto à crítica à fixidez e ao pensando da ideia de rompimentos ou de fluxos, com base nas leituras de Foucault (2007), Rolnik (2018), Guattari (2009; 2012), Pelbart (2016) e nas acepções destacadas no texto, esquematizamos uma compreensão exemplificadora das técnicas/tecnologias de dominação e das subjetividades, a qual está equacionada a seguir:

- A noção de Sujeito / técnicas ou tecnologias: gera uma ilusão da autonomia, do autodomínio e da individualidade. É do domínio identitário. $\mathrm{Da}$ ordem das formas. Estagna ou interrompe processos contínuos de diferenciação e multiplicidade. O self kantiano é seu exemplo por excelência. O sujeito ecológico padrão advém dela. 
- A noção de Subjetividade / técnicas ou tecnologias: possibilita um modo de pensar por atravessamento e fluxos, entre os quais, os discursivos. É do domínio dos processos de identificação. Da ordem das forças. Permite processos contínuos de diferenciação e multiplicidade que operam por subjetivação/desubjetivação. As experiências ambientais de grupos periféricos e as pessoas que não se autodenominam ecológicas, mas operam por relações éticas para a vida social e ambiental, encontram-se mais próximas dessa gama.

Embora sintéticas, essas explicações corroboram a desconfiança e a problematização do sujeito ecológico em sua perspectiva de figura identitária fixa.

De acordo com Rolnik (2018), o sujeito fixo tem sua experiência reduzida nas trocas e performatividades que estabelece com o mundo, pois opera por reiteração, inclusive, de discursos, de normas e de trajetos existenciais repetitivos que continuam por capturar sua força produtiva nas modalidades típicas do capitalismo financeiro e globalizado. Logo, a rigidez identitária atribuída à figura do sujeito ecológico funciona como um dispositivo ${ }^{5}$, ou seja, como um mecanismo de controle repetitivo e incessante de normas ambientais que servem a determinados interesses e ideologias, muitas vezes, econômicos, monetarizados e escalados como valores ecológicos universais.

Para elucidar, podemos dizer que alguns efeitos da norma são: "[...] relacionar os atos, os desempenhos, os comportamentos singulares a um conjunto" e "fazer funcionar, através dessa medida 'valorizada', a coação de uma conformidade a realizar" (FOUCAULT, 2013b, p. 175). Sob esse prisma, a norma estabelece um campo de comparação, de diferenciação e regras a serem seguidas.

A normatividade sempre enuncia e reitera o sujeito, que tem a própria conduta ambiental como o objeto alvo dos dispositivos ecológicos. Segundo Maknamara (2012), o dispositivo visa à constituição da maneira pela qual os sujeitos se descrevem, narram-se, julgam-se e se controlam. Se o dispositivo é ecológico, ele não apenas ensina o que constituiria a ecologia, mas como as pessoas devem aprender a ser ecológicas em relação às práticas que regulam suas experiências ambientais, em relação ao reconhecimento como sujeitos dessas experiências e pelo exercício de um autogoverno ou de uma ecogovernamentalidade (INOCÊNCIO, 2019) que seleciona e controla o que deve ou não ser feito e praticado ambientalmente.

5 Para Foucault (2014b), dispositivo é uma rede heterogênea que engloba discursos, instituições, decisões regulamentares, leis, medidas administrativas, enunciados científicos, proposições filosóficas etc. Está alicerçado pelas dimensões do saber, do poder e da produção de modos de subjetivação. O dispositivo é da ordem da norma, da reiteração, do controle. 
Vale frisar que a ecogovernamentalidade é uma prática de biopoder e de governo biopolítico ${ }^{6}$. Se a biopolítica foi a invenção das sociedades liberais, no capitalismo neoliberal temos a consagração da ecopolítica e da governamentalidade verde - desenvolvidas como práticas de governo na segunda metade do século XX e na virada do milênio, especialmente com a inauguração da discursividade de monitoramento da vida considerando os fluxos planetários e a relação econômica com os recursos ambientais (MALETTE, 2011; VEIGA-NETO, 2014; SIQUEIRA, 2016; INOCÊNCIO, 2019).

Nesse aspecto, conforme se fabrica o sujeito ecológico contemporâneo, certas condutas normativas também são adaptadas, tais como: separar o lixo orgânico de materiais inorgânicos recicláveis; evitar a compra de alimentos em bandejas de isopor; evitar sacolas plásticas; valorizar as empresas investidoras de pacotes ecológicos direcionados à formação de seus funcionários e as indústrias que fabricam e comercializam produtos verdes ou sustentáveis, prezando, inclusive, pela economia, pelo consumo consciente e pela minimização do desperdício em todos os âmbitos da vida pessoal ${ }^{7}$.

Tais condutas aparentemente correspondentes aos apelos ambientais decorrem, no entanto, das tecnologias de dominação que capturam as singularidades e homogeneízam os hábitos e as formas de ser/estar/responder à crise ambiental como práticas padronizadas. Essas práticas, contudo, nem sempre se adensam em projetos políticos emancipatórios, pois também reiteram outros dispositivos e normas das pedagogias ou dos empreendimentos verdes ligados substancialmente à macroeconomia, negligenciando, segundo apontam Melo e Souza (2014), os princípios libertadores e humanitários da Educação Ambiental crítica, emancipatória, ontológica e coletiva, e as compreensões de que as respostas aos ambientes são polivalentes e correlacionadas à vida experienciada nos próprios locais de interação ambiental.

Nossos apontamentos não são os de um viés moral. Não indagamos e nem afirmamos que o processo identitário que caracteriza o sujeito ecológico seja bom ou mau, positivo ou negativo. Antes, conforme Foucault, admitimos que o poder e as discursividades possuem caráter produtivo ao fabricar os sujeitos dos quais falam, os saberes e poderes que Ihes atravessam, o que se espera

\footnotetext{
${ }^{6}$ A biopolítica tem como alvo o governo da população; ela é uma prática de saber e poder que opera pelos biopoderes. O biopoder produz tecnologias de controle, normatização e disciplinamento populacional com foco na vida governável, na regulação do indivíduo e do coletivo social, na segurança de territórios e ambientes, na gestão política da sexualidade e do corpo, das taxas de natalidade, da ocupação demográfica e da mortalidade, entre outras (FOUCAULT, 2010).

7 Não dizemos que tais práticas não tenham valor na mitigação de impactos ambientais e na consolidação de relações menos utilitárias para com a natureza e para com as pessoas. Enfatizamos, entretanto, que elas partem de instâncias maiores e, muitas vezes, são repetidas cotidianamente na reiteração - acrítica e apolítica - de normas ditas ambientais. Elas aplacam a consciência do sujeito que se deseja ecológico e salvador do mundo, sem, contudo, resultarem em interferências e mudanças nas grandes corporações capitalistas que conformam a maioria dos problemas ambientais tanto em nível local quanto planetário.
}

Revbea, São Paulo, V.16, № 5: 94-114, 2021.

revista brasileira

educação ambiental 
como conduta, os modos de vida e as formas identitárias a responder determinadas problemáticas da história. Por essa lógica, podemos pensar que há diferentes dispositivos, atravessamentos, fluxos e gradações que vão produzindo diferentes modos de ser e hábitos, por meio dos quais as pessoas se identificam como ecológicas, em maior ou menor escala, ou apropriam-se deles para, inclusive, contestá-los e refutá-los. Logo, o sujeito ecológico responde, então, à ideia de crise ambiental.

Porém, essa figura identitária tornou-se, entre tantas facetas, um slogan pouco problematizado, capturado por inúmeras instâncias e instituições em processos que desprezam as singularidades e os atos de criação imanentes às diferentes possibilidades de se dialogar com a vida nas relações trocadas com os ambientes. Por esse prisma, quando as técnicas de dominação se sobressaem, é a fabricação do sujeito ecológico orientado por protocolos fixos que está em questão. Com sua experiência reduzida exclusivamente à modalidade de sujeito, este se torna passivamente um efeito desejável de instâncias como o Estado e o mercado globalizado e cumpre um valor social (e, principalmente, econômico), desde que ceda a capacidade produtiva de seu corpo e crie o substrato ideal para que as instâncias hegemônicas continuem operando e, consequentemente, produzindo os discursos que atravessam as vontades das pessoas ditas ecológicas.

Em contraponto, podemos dizer que, quando as técnicas de si se sobressaem às técnicas de dominação, são criadas brechas de possíveis territórios existenciais marcados pela ressignificação do modo de olhar os ambientes e de construir o oikos. O sujeito não reitera; ele se pensa, modificase, busca para si outra subjetivação ambiental. Para Guattari (2012), essa vertente da subjetivação - e não da figura cristalizada do sujeito ecológico tange a possibilidade de emergência de mundos virtuais, de ecologias virtuais, isto é, de ecologias não cartografadas pelos padrões dominantes, a saber: os processos relacionais baseados em economias de cooperação simbólicas com os ambientes e as pessoas, a biodiversidade encarada em termos associativos e desencadeadores de memórias subjetivas e também na dinâmica das relações humanas, o desapego das macro visões homogeneizadoras dos modos ecológicos plurais presentes em nossos espaços e lugares, entre outras intensidades e modos de se praticar a relação ética ambiental.

Apresentadas essas conceituações, alguns questionamentos podem ser levantados: que razões levaram as sociedades ocidentais à necessidade da criação do sujeito ecológico e como este se apresenta na atual conjuntura? Por que a figura identitária do sujeito ecológico prevalece quando comparada com as formas de construção subjetivas mais livres e criativas? A quem interessa a figura identitária - de trajetos existenciais e modos repetitivos ensejados pelas normas - do sujeito ecológico?

Uma via de entrada que responde a essas questões é o fato de que a modernidade nos privou de um regime sensível e ético (no sentido de práticas voltadas a si mesmo, do cuidado de si). Encontra-se em questão um modo de 
vida ecológico em sua expressão mais empobrecida, porque provém, justamente, de vetores articulados "de cima para baixo", ou seja, do Estado, das instituições jurídicas, científicas, do mass media e dos setores de mercado, fabricantes de discursividades e de ideários verdes.

$\mathrm{Na}$ roupagem verde, o Homo oeconomicus não conhece mais o meio ambiente pela epiderme, pelo cheiro e pelas glândulas, mas pelas mediações das máquinas sociais que realizam - e o conectam a - um tipo de tradução do que seja esse meio, diga-se, transformado por enunciações (representações, ilustrações, leis, códigos de preceitos, agendas ecológicas) e aparatos não discursivos (a arquitetura da natureza, das instituições, os acontecimentos políticos, a organização das relações natureza-economia-sociedade-cultura e todas as práticas aí implicadas) em recurso/discurso natural para ser consumido ou manifesto em bandeira identitária ecológica.

No caso do sujeito ecológico já capturado pelas investidas do mercado perde-se, portanto, a conversão de si em outra coisa. Ele é apenas blocos de verdades e saberes estanques performadores da figura do sujeito que age por uma consciência ecológica, é efeito de discursos - dos quais, muitas vezes, ele próprio desconhece o viés ideológico e a perspectiva reiterativa de uma verdade ambiental. Sem o pensar e o cuidado de si, esse sujeito converte seus atos em práticas aceitáveis e favoráveis ao sistema.

Esse quadro político-subjetivo do Homo oeconomicus dialoga com a noção guattariana de subjetividade modalizada. Para Guattari (2009), essa modalização é caracterizada por uma subjetividade capitalística formatada não apenas por ideias que nos chegam via instituições como a mídia, a família ou qualquer outro equipamento que nos rodeia, mas por enunciados significantes traduzidos por um sistema de conexão direta entre, de um lado, as grandes máquinas produtoras de controle social e, de outro, as instâncias psíquicas que perfazem nossas maneiras de perceber o mundo. Entre os enunciados dessa subjetividade capitalística destacam-se: a culpa e a cobrança por não se dispor como agente de transformação ambiental, a rendição ao marketing verde das corporações, a adoção de estratégias que legalizam e respaldam o consumo de uma série de produtos supérfluos, porém ecologicamente certificados e etiquetados por instituições que trabalham para esse fim.

Em suma, nossa crítica aponta para o enredamento identitário que caracteriza o sujeito ecológico, lendo-o como decorrente de territórios nos quais boa parte daqueles que se declaram inventivamente verdes estão, na verdade, mergulhados em diagramas já fabricados e oferecidos como um tipo de serviço "prêt-à-porter", que se caracteriza menos como espaço para as subjetividades criativas, para as experiências emancipatórias capazes de resolver os conflitos ambientais, mas, cada vez mais, está direcionado às multidões que respondem ao chamado das máquinas e das modalidades de vida dispostas na nova etapa do capitalismo moderno, ou seja, esta etapa na qual o neoliberalismo não cessa de se vestir de desenvolvimento sustentável ou de ecologicamente correto. 


\section{O sujeito ecológico como acontecimento}

As considerações realizadas até aqui são fundamentais para o entendimento acerca da figura identitária do sujeito ecológico a partir de seu acontecimento na história e no tempo presente. Para se compreender, no entanto, a configuração do processo identitário caracterizador do sujeito ecológico, colocamos em evidência a proliferação discursiva da ideia de crise ambiental e seus efeitos na construção das subjetividades no tempo presente.

Em nosso ponto de vista, a ideia de crise ambiental tem seu fabrico a partir da segunda metade do século XX, em diversas circunstâncias históricas, econômicas e ambientais que estiveram relacionadas com a construção da ecologia, do movimento ambiental, do direito ambiental e das políticas públicas, entre outros, como campo discursivo político e um território de disputas perpassado por relações de saber e de poder estabelecidas socialmente. Dessas, podemos citar: a percepção da esgotabilidade dos recursos ambientais; os movimentos sociais feministas, negros, antibelicistas e de contracultura que reivindicam valores diferenciados da sociedade industrial e não objetificadores; o estabelecimento das políticas ambientais nas três últimas décadas do século XX; as agendas governamentais e civis para a sustentabilidade; a conformação de um capital ecológico; os marcos de regulamentação ambiental para indústrias e para o agronegócio; e a conformação da Educação Ambiental como política pública.

Mas na perspectiva de aparecimento de um acontecimento histórico, um acontecimento é um conjunto de situações que estabelecem uma nova relação discursiva.

A noção de acontecimento, importada de Foucault, pode ser lida como novidade, diferença e, também, como prática. As chamadas novidades (discursivas ou não) instauram novas formas de regularidades, novas ordens mundiais, de maneira que a passagem de uma verdade histórica à outra ou de uma episteme (como ele nomeia um bloco de saberes que caracteriza uma época) à outra instaura condições para a emergência de enunciados, práticas e acontecimentos que se alternam entre regularidade e ruptura e definem as transformações da atualidade (FOUCAULT, 2013b; 2014b). Sob esse prisma, importa pensar "o que é a nossa atualidade?", "qual é o campo atual das experiências possíveis?", diante das ordens dos discursos, e "qual a nossa compreensão do presente ou como se fez a ontologia da atualidade?".

$\mathrm{Na}$ atualidade, o sujeito ecológico tornou-se um ethos, ou seja,

[...] uma atitude (...) uma maneira de relacionar-se com a realidade atual, a opção voluntária pela qual optam algumas pessoas na maneira de pensar e de sentir; uma forma de atuar e conduzir-se que ao mesmo tempo marca a relação de pertinência e de apresentação de si mesma como uma tarefa (...) (FOUCAULT, 2014c, p. 295). 
No entanto, esse ethos se orienta mais pela sobreposição de práticas de dominação do que, propriamente, por um cuidado ético como "um tipo de relação que você deve ter consigo próprio, [...] e que determina como o indivíduo se constitui como sujeito moral de suas próprias ações" (FOUCAULT, 2014c). A noção de "consigo próprio" que consagra a responsabilidade "pelas próprias ações" deriva da noção de indivíduo, nascida como fio condutor na intelecção da racionalidade política do século XX. Na perspectiva foucaultiana do sujeito como acontecimento histórico, faz-se necessário situar que foi "a partir do final do século XIX que a figura de indivíduo pôde se configurar como loco privilegiado da ação do governo" (SAMPAIO, 2019, p. 66), figurando como objeto e produto das práticas de condução e objetificação.

Além disso, para que essa figura identitária tenha seus contornos acentuados, deve-se pensar tanto no acontecimento arqueológico como no acontecimento discursivo. O primeiro "quer dar conta da novidade histórica; o segundo, da regularidade histórica das práticas" (CASTRO, 2014, p. 24).

Em nossa problematização das práticas ecológicas, dizemos que 0 acontecimento arqueológico se caracterizaria, de uma maneira geral, pelo marco inaugurado com a ruptura de parte da sociedade ocidental com os saberes e modos de vida intensificados pelo capitalismo industrial e pelo predatismo ambiental, contrapondo-se a estes por meio da adoção de estilos de vida e políticas sociais ativadoras da preocupação ambiental. Por outro lado, a segunda perspectiva do acontecimento está discursivamente galgada nos novos saberes, orientando práticas que aludem às posições dos sujeitos ecológicos. Ambos, porém, possuem a mesma linha em comum: a novidade ecologia instaurando condições de acontecimentos e a regularidade das práticas ambientais.

O conceito de acontecimento oferece elementos para o entendimento de que a emergência de novas formas de enunciação, numa dada sociedade, articula-se com acontecimentos que não são restritos à natureza discursiva, mas podem ser também de ordem econômica, social e política, de forma que orientam os modos de vida.

No que tange à aparição do sujeito ecológico propriamente dito, Carvalho (2000) considera sua invenção um marco decorrente da tradição ambiental ou, ainda, um território simbólico que envolve uma trama de sentidos e temporalidades capazes de produzir auto posicionamentos para os sujeitos no mundo. Nesse sentido, um horizonte histórico, caracterizado por um tipo de ideal ou por uma utopia societária, é anterior aos processos ou aos perfis identitários que perfazem o jogo dessa tradição. As condições políticas e sociais anteriores ao denominado movimento ambiental já favoreciam - discursivamente - a emergência do conservacionismo, do imaginário da natureza moderna intocada, do retorno a uma conexão mítica com os ambientes, do ideário de garantia de vida e de proventos para o mundo futuro, do cuidado ético com o planeta e da patrulha das condutas para se prover uma boa relação com o espaço ambiental vivido. 
Nessa perspectiva, traçando um paralelo com o surgimento da figura do soldado, descrita por Foucault (2013a, p. 131), na obra "Vigiar e Punir", o sujeito ecológico "[...] se tornou algo que se fabrica; de uma massa informe, de um corpo inapto, fez-se a máquina de que se precisa [...]"; um soldado, ou seja, uma "polícia ecológica".

Embora a categoria sujeito ecológico possa ser lida como um modelo ético para se estar no mundo (CARVALHO, 2000), o termo ético, a nosso ver, está empregado mais em um sentido de sujeição, decorrente da legitimidade atribuída às correntes ou aos movimentos ecologistas despontados na década de 1970 , do que, propriamente, no sentido de uma prática de liberdade na qual o sujeito conduz sua vida junto aos aspectos éticos e políticos da questão ambiental. Atravessado pelos feixes discursivos de uma crise e de um modelo éticoambiental universal, o sujeito ecológico treina suas condutas para executar funções, tarefas, posturas e práticas a reverberar os interesses dos grupos hegemônicos.

Por outro ângulo, entre as múltiplas faces desse sujeito efeito de discursos, também fulgura a de

[...] um herdeiro da cultura socialista e da crítica marxista à ética utilitarista. Protagoniza um movimento histórico e um novo paradigma da ação política capaz de unificar o campo dos novos movimentos sociais num movimento mais abrangente (CARVALHO, 2000, p. 185).

Essa configuração identitária de caráter sócio marxista e contrária ao utilitarismo esteve, no Brasil, ligada a um segmento da sociedade civil organizada composta por pessoas dotadas de alta escolaridade que, no início de sua formação, adotou como base o caso do Fórum Brasileiro de ONGs e os Movimentos Sociais preparatórios para a Rio-92. A categoria sujeito ecológico, na visão de Carvalho (2000), é também entrecortada por um corte geracional, podendo ser caracterizada: a) pelos fundadores das discussões (pessoas com mais de 55 anos); b) pela primeira geração pós-fundadores (pessoas com 35 anos ou mais); e c) pela segunda geração pós-fundadores (abaixo de 35 anos).

Ao destacarmos parte dessa genealogia histórica do sujeito ecológico, evidenciamos que não se trata de uma forma de subjetivação que esteve "desde sempre aí", quer a entendamos pelo aspecto de uma herança advinda dos conflitos ambientais, segundo o viés marxista crítico ou, quiçá, pelos afáveis apelos ao retorno à natureza ou às defesas do equilíbrio economia-ambiente. Antes, elucidamos o seu caráter de acontecimento histórico, de um aparecimento, por meio do qual se deflagrou uma ruptura (da ideia de uma eterna renovação dos recursos dos ambientes para o paradigma da esgotabilidade, por exemplo) em fluxos contínuos de situações sociais. Dito de outra forma, ecologia e sujeito ecológico criaram-se concomitantemente, e não 
há sustento do discurso ecológico sem os dispositivos que atravessam seus sujeitos e sem as ações reiterativas destes - o sujeito é um acontecimento, ou seja, não há o sujeito da ecologia sem a ideia de crise ecológica e ambiental.

\section{Estado-mercado e ambiente: a articulação policial do sujeito ecológico}

Os Estados-nação e as posições ideológicas do mercado fabricam a figura do soldado ecológico, ou seja, do sujeito ecológico que exerce práticas e condutas de patrulha e vigília dos ambientes.

Preocupado em mapear e transformar as condutas populacionais em aferição, por meio de estatísticas, ao menos desde o século XVIII, o Estadonação, na interface meio ambiente, tem operado sobrepondo as noções de população, segurança, economia política e ambiente. Foucault apontou que o Estado percebe que a incitação política dos indivíduos amplia suas táticas de poder, pois, nessa conformação, não há somente a grande instância do poder, mas uma ampla circulação acionada nas microinstâncias individuais - as sujeições participativas, tolerantes e resilientes.

$\mathrm{Na}$ atual configuração da crise ambiental, não há apenas a grande instância de vigilância Estado agindo no patamar social, mas, sim, microinstâncias móveis e circulantes responsáveis por atualizar a discursividade ambiental sob efeito de uma polícia, de uma vigília inculcada nas subjetividades circulantes.

Tal discursividade tende a perscrutar e a se preocupar com as práticas ecológicas que devem ser reiteradas socialmente. Como aponta Passeti (2013, p. 16), multiplicam-se as polícias e estimula-se em cada cidadão sua vocação para policial, de modo que seja possível falar em uma "polícia da vida" (ou verde) que, quando convocada a participar, "cuida tanto dos vivos em sua área, quanto do planeta e da vida dentro e fora dele". Por efeito, a incitação do cidadão-polícia, do cidadão comum assujeitado pelas forças do Estado e pelas subjetividades reiteradas, faz com que o sujeito perpassado pela preocupação ambiental se torne o modelo de sujeito ecológico no âmbito de quem interroga e faz o exame de sua consciência, mas também de quem regula os hábitos de outrem por meio de "[...] 'reivindicações de verdades' sobre modos ecológicos de conduta pelos quais se espera que indivíduos racionais governem a si e aos outros" (MALETTE, 2011, p. 14).

Nesse contexto de ecogovernança, a própria noção de um presente ambiental passa a ser ressignificada, de acordo com "[...] práticas voltadas ao futuro melhor de si e do planeta" (PASSETTI, 2013, p. 12). Da segurança territorial incitada pelas práticas de Estado, as políticas e os discursos passam a dar foco maior na "segurança da população", transferindo a noção de "segurança pelas armas para a segurança pelo desenvolvimento humano sustentável" (RODRIGUES, 2012, p. 14). 
O efeito mais pernicioso dessa polícia é a imposição de um risco para as diferentes pessoas e suas subjetividades de classe social, de gênero, de idade, de profissão e de pertencimento ambiental. Ela apaga os modos subjetivos de ser quando considera as relações éticas e a problematização daquilo que as pessoas praticam e escalonam como conduta ecológica, pois, nem todo mundo, nem todo grupo social identifica-se ecologicamente da mesma forma e desenvolve as mesmas práticas ambientais. Isso implica, por exemplo, políticas persecutórias para aqueles que agem diferentemente das crenças e dos modismos fabricados em prol da seguridade dos ambientes ou para aqueles cujas práticas são modalizadas mais fortemente por suas subjetividades, em outras palavras, àqueles que escapam da norma.

Logo, o governamento das vidas orientado pelo Estado produz uma série de políticas, campanhas e planos que não cessam de promover uma profilaxia social das populações e das subjetividades, em momentos considerados necessários para a intervenção social. Os efeitos interventivos nas formas de subjetivação e gerenciamento das vidas tornam-se marcantes em momentos de epidemias, escassez de recursos ou propagação de doenças, e ganham forma nas campanhas impulsionadas por projetos do Estado, sobretudo em instituições como as escolas, nas instâncias televisivas e radiofônicas, nas redes sociais e na própria regulamentação da política ambiental. Nessa dinâmica, a figura identitária do sujeito ecológico, especialmente o que patrulha, ensejada pelas forças do Estado, torna-se um componente necessário do governo populacional, tendo a segurança planetária ambiental como justificativa.

Como exemplo de instâncias de governamento que conduzem os comportamentos ecológicos por parte do Estado-nação e que perfazem uma agenda nacional de práticas, podem ser citadas, em ordem cronológica, a Secretaria Especial de Meio Ambiente (SEMA), criada em 1973; a Política Nacional de Meio Ambiente (Lei no 6.938), criada em 1981; o Ministério do Meio Ambiente (MMA), em 1985; a própria Constituição Federal $^{8}$, versão de 1988; O Instituto Brasileiro de Meio Ambiente e Recursos Naturais Renováveis (IBAMA), criado em 1989; o Fundo Nacional de Meio Ambiente, de 1990; o Programa Nacional de Educação Ambiental (ProNEA), cuja primeira edição data de 1994; a Rio-92, a série de documentos ${ }^{9}$ provenientes desse evento e seus efeitos posteriores, a saber, a criação da Coordenação Geral de Educação Ambiental

\footnotetext{
${ }^{8}$ Referência ao trecho do Art. $225, \S 1^{\circ}$, inciso $\mathrm{VI}$, que "assegura o direito de todos ao meio ambiente ecologicamente equilibrado, bem de uso comum do povo e essencial à sadia qualidade de vida, atribuindo ao Estado o dever de "promover a Educação Ambiental em todos os níveis de ensino e a conscientização pública para a preservação do meio ambiente"'.

9 Destacam-se a Agenda 21, a Convenção sobre Diversidade Biológica, a Convenção das Nações Unidas de Combate à Desertificação, a Convenção-Quadro das Nações Unidas sobre as Mudanças Climáticas, a Declaração de Princípios sobre Florestas e, no âmbito não oficial (isto é, que decorreu das reuniões da população civil organizada, de forma paralela às reuniões entre os chefes de estado), a Carta brasileira para a Educação Ambiental, a Carta da Terra e o Tratado de Educação Ambiental para Sociedades Sustentáveis e Responsabilidade Global, todos decorrentes do ano de 1992.
}

Revbea, São Paulo, V.16, № 5: 94-114, 2021. 
do MEC (COEA) e da Diretoria de Educação Ambiental (DEA), instituídos pela Política Nacional de Educação Ambiental (Lei no 9.795), de 1999, por sua vez, integrados pelo Departamento de Educação Ambiental do Ministério do Meio Ambiente; o reconhecimento do meio ambiente como tema transversal inserido nos Parâmetros Curriculares Nacionais, em 1997, e a Rio +20 (Conferência das Nações Unidas sobre Desenvolvimento Natural), sediada no Brasil em 2012, vinte anos após a Rio-92.

Em hipótese alguma desprezamos a importância que tais instâncias de governamento desempenham em termos de gestão, de preservação ambiental e de ações de fiscalização sobre a depredação dos recursos, sobretudo, nos últimos anos, quando temos assistido à relativização dos dispositivos legais, aos cortes de secretarias, ao desagendamento ambiental e às demissões em cargos que inspecionam as práticas impactantes nas regiões brasileiras (principalmente, nas localizadas distantes dos centros urbanos).

O intuito, antes, é aludir aos saberes e aos poderes da instância Estado implicados na performatização do sujeito ecológico. Desse modo, o problema apontado não se reduz ao papel estatal per se, mas amplia-se para as relações políticas e efeitos que daí decorrem. Dito de outra maneira, poderíamos pensar a agenda ambiental brasileira, criada e sistematizada desde 1970, como transformadora do país que reivindicava o seu direito de poluir para se desenvolver, em um Estado de lobbys ambientais e de grandes investimentos agroindustriais, imobiliários e desenvolvimentistas que capitaneiam, em nossa atualidade, a usurpação de terras, o uso indiscriminado de defensivos agrícolas, a invasão de reservas naturais, a eliminação das relações ecológicas nativas e tradicionais e das diversidades entre humanos e ambientes, entre outras situações que sabemos escamoteadas pela repetição das condutas ecológicas desejáveis e pelas práticas alijadas e alienadas da realidade subjacente.

Se pensarmos, ainda, em termos de seus efeitos pedagógicos, tal agenda ambiental incitou a reprodução de sujeições presentes e legitimadoras do Estado, para que modos de agir fossem postos em prática, caracterizando identidades pouco criativas e muito alienadas das realidades locais, tampouco participantes da resolução dos problemas globais, ou seja, mentes, posturas e ações que só agem por meio de comandos institucionalizados. Entre essas, podemos citar a preocupação ambiental em datas previamente sugeridas por escolas ou nos pacotes empresariais, as representações de felicidade ao se defender $\mathrm{o}$ ambiente e se cumprir com a responsabilidade delegada às economias e propagandas sobre os usos racionais dos recursos sem a conscientização de que os maiores consumidores planetários de água e energia encontram-se, justamente, em meio aos lobbys e negócios que devastam biomas e ecossistemas ou a própria ação de policiar a conduta ambiental praticada socialmente com a falácia da reciclagem e do consumo de produtos verdes.

Essas táticas de governamento das vidas, incitadas por práticas de mercado, não são contrárias ao desejo por saber e poder do Estado. Ao 
contrário, estabelecem-se em uma função de governo capaz de garantir as contrapartidas e os contrapesos de liberdades que já apareciam, anteriormente, no liberalismo, de modo que é o mercado que surge como "locus de produção de verdades" por meio da economia política (FOUCAULT, 2010) e da economia ambiental. Em outras palavras, nas sociedades hodiernas, a gestão tem como modelo os processos econômicos, especialmente, o funcionamento e a regimentação que atendem ao mercado, ou seja, "o governo da população terá como objetivo fazer com que a sociedade funcione como o mercado" (SAMPAIO, 2019 , p. 76). Portanto, nas práticas do mercado, o "descolamento" dos pressupostos políticos provenientes dos movimentos sociais ecologistas e sua transformação em etiqueta verde estão ainda mais evidentes.

Se desde o liberalismo do século XIX, a noção de indivíduo passava a ocupar um lugar privilegiado na análise política, agora, ela autoriza "uma razão de governo produtora de liberdades, mas isso porque ela é também consumidora de liberdade" (SAMPAIO, 2019, p. 71, grifos nossos). Em termos de subjetivações ambientais, pode-se dizer que "a existência presente constrói uma experiência fundada no 'eu', e a expectativa futura se expressa em um projeto de triunfo individual' (SAMPAIO, 2019, p. 82), uma espécie de self-made man neoliberal e, ao mesmo tempo, ecológico.

Um dos conceitos consagrados nessa dobra Estado-mercado e no contexto de surgimento da crise ambiental é o de desenvolvimento sustentável. Esse conceito foi fabricado como termo chave no capitalismo neoliberal. Segundo Passeti (2013), o mesmo conceito evidencia que o alvo não é mais manter a condição de pobreza, mas elevar os indicadores econômicos, aferir índices de felicidade e desenvolvimento humano (saúde, educação e cultura), disseminar uma cultura de paz, educar pessoas e promover práticas de resiliência, instituir uma economia verde, encontrando certa qualidade de vida com redutores de vulnerabilidades e gerando condições compartilhadas para uma vida melhor de pessoas e ambientes. Para tal, o mercado investe, agora, em slogans como segurança e securitização, conservação do planeta, ou seja, ele se mune de enunciações e estratégias discursivas voltadas ao convencimento de que tal condição está na proposição da vida resiliente e engajada do cidadão-polícia da ecologia.

O mercado, portanto, não apenas anuncia o seu produto ao nicho específico dos sujeitos ecológicos, mas cria sua própria demanda, sua própria visão de crise, à medida que disciplina os corpos, mas também seduz, incita, controla as almas, as vontades e as performances ecológicas. Slogans alusivos aos problemas planetários que interpelam e modulam as vontades do sujeito ecológico perfazem, então, uma correlação de forças atravessada por enunciados como:

"Reciclar para transformar" (Natura Cosméticos, 2009); "Promover o uso consciente dos recursos naturais é um dos objetivos do Santander" (Banco Santander, 2009); "Nosso Planeta está ficando cada vez mais poluído; cada vez mais 
quente" (Rede de Supermercados Modelo, 2009); "Tomar uma decisão para cuidar do planeta" (Banco do Brasil, 2009); "Todos pelo Planeta" (Editora Abril. Revista Cláudia, 2010); "Salve o Planeta! Uma hora vai voltar para você. Conserve seu Planeta, ainda dá tempo!" (Campanha WWF, 2010) (SILVA; VIEIRA; HENNING, 2012, p. 6).

A leitura crítica desses enunciados nos permite depreender que a ideia de desenvolvimento sustentável propaga uma difusão do temor, apostando em mensagens de responsabilidade - catastróficas e apocalípticas - que tensionam os sujeitos que, por efeito, passam a consumir os produtos e os serviços das marcas ditas ecológicas, aplacando suas culpas e direcionando suas práticas como se algo de irremediável fosse acontecer caso não o fizessem. Afinal de contas, com tais chamadas, também operadoras de policiamentos e de vigílias sobre as condutas, "torna-se difícil resistir a não participarmos da ordem do discurso de crise ambiental tão em voga na contemporaneidade" (SILVA; VIEIRA; HENNING, 2012, p. 7). A contradição não tão evidente no discurso de patrulha ecológica: os enunciados citados e semelhantes a circular em nossa sociedade propagam a redução do consumo numa relação ética e política.

Nessa contradição imperceptível, o mercado tergiversa (e reduz) a problemática ambiental por meio da opção do consumo personológico e do investimento em slogans que dialogam com esse sujeito sensibilizado pelas questões ambientais. O efeito perverso dessa estratégia é, portanto, a coincidência do sujeito ecológico com a ação individual salvacionista; ele se vê agente policiador da causa, mas não está na ação efetiva de se questionar como invenção e acontecimento da modernidade, da crise ambiental e, menos ainda, dos moldes capitalistas e das frentes neoliberais que incentivam o consumo.

Por fim, é evidente a existência de casos nos quais as ações do sujeito ecológico, em combate a certas problemáticas ambientais, tenham sido reconhecidas como imprescindíveis na experiência de determinados países ou locais. No entanto, tencionamos evidenciar a ação do poder na produção de relações e saberes ambientais e de sujeições endereçadas ao ecogoverno da população.

Voltando ao Brasil, por exemplo, a tradição ambiental (CARVALHO, 2000) foi produzida à toque de caixa para satisfazer os câmbios e negociatas entre o país e nações industriais do norte global. O discurso ecologista já estava incorporado no imaginário dos países nominados, nas décadas de 1970 e 1980, de primeiro mundo (GONÇALVES, 2008). Logo, importava a esses governos a adoção de um sistema legislativo e comportamental ecológico por parte do povo brasileiro, ainda que, nas esferas hegemônicas, o Brasil estivesse requerendo para si o direito de se industrializar às custas da poluição e da exploração ambiental.

Essa projeção de tradição ambiental também fabricada colabora para fortalecer o posicionamento que embasa a crítica proposta neste texto, isto é, o

revista brasileira educação ambiental 
ponto de vista de que nossas condutas ecológicas foram construídas mais pela via de uma moral coercitiva e policialesca do que pelo exercício ético de se pensar nossa atualidade, de se performar outras condutas para a sujeição e subjetividade ecológica e de criar a si mesmo, ou seja, de criar e validar as intermediações ambientais diferenciadas da ordem e da norma.

\section{Conclusões}

Por um lado, o sujeito ecológico emerge como acontecimento histórico, reificado por incessantes práticas de dominação, discutidas, aqui, a partir das figuras do Estado e do mercado que ditam um lugar para o sujeito.

Por outro lado, a noção foucaultiana de acontecimento também pode ser concebida como um infinitivo acontecer da liberdade, um trabalho incessante e inacabado de pensar a si mesmo no tempo presente e de criar novas discursividades; tal prática de pensamento comporta a possibilidade de liberdade, isto é, de pensar e atuar diferente do que se pensa e do que se é.

Nossa crítica voltou-se, portanto, ao questionamento acerca da universalidade do sujeito ecológico, uma vez que nem todas as pessoas se identificam com os modos objetificados do mercado e do Estado nas padronizações de um único modo ecológico de ser. Nos apontamentos e problematizações das contradições da categoria sujeito ecológico, podemos, inclusive, buscar as diferentes nuanças de pensamento e de atitude ambiental, considerando os atravessamentos da ordem da experiência coletiva, do fluxo e das subjetividades vivenciadas.

Em nosso entendimento, o sujeito ecológico não precisa resumir-se a uma figura identitária cristalizada, pois pode ser construído por práticas de liberdade buscadas no pensar da atualidade. Para que isso aconteça, todavia, será preciso encarar o acontecimento do presente como uma "crítica prática de uma transgressão possível" (FOUCAULT, 2014c, p. 300).

A produção de uma especificidade de crise ambiental defendida pelo Estado e pelo mercado resultou na dispersão de enunciados ecológicos fabricadores de práticas discursivas, de ações e das condutas ambientais dos sujeitos, muitas delas assujeitadoras de indivíduos pela ordem da dominação como: a ideia de polícia ambiental ou de ocupação de um local politicamente correto nas cadeias ecológicas, ao mesmo tempo, contraditoriamente, em que se ocupa o lugar estratégico nas cadeias de consumo e o distanciamento da relação ética e singular para com os ambientes. Portanto, "o sujeito ecológico, tendo sua experiência reduzida exclusivamente na modalidade de sujeito, tornase um efeito desejável da ecogovernamentalidade" (INOCÊNCIO, 2019, p. 34).

Tomando os discursos e os poderes como produtores de efeitos, apontamos ser preciso pensar a ordem dos atravessamentos dos saberes e poderes na presentificação política de nossos modos de ser ecológicos, sobretudo, para se constituir outros efeitos e condutas. Isso requer a mobilização 
de fluxos e de intensidades ambientais diferenciados e contra-hegemônicos e a desestabilização dessa figura intencionalmente criada do sujeito ecológico, que nunca está isenta das contradições e dos conflitos da sua atualidade, mas pode, por outras vias, negociar suas próprias políticas e suas agendas ambientais subjetivas ao romper com as reiterações ecológicas normativas.

\section{Referências}

BENITES, F. R. G. Do cuidado de si à escrita de si: Foucault e o sujeito em construção. In: GUERRA, V. M. L.; NOLASCO, E. C. (orgs.). Michel Foucault: entre o passado e o presente, 30 anos de (des)locamentos. Campinas, São Paulo: Pontes Editores, 2015.

BUTLER, J. Problemas de Gênero. Rio de Janeiro: Civilização Brasileira, 2003. CARVALHO, I. C. de M. A invenção do sujeito ecológico: sentidos e trajetórias em Educação Ambiental. 349 f. Tese (Doutorado em Educação) - Universidade Federal do Rio Grande do Sul. Faculdade de Educação. Programa de PósGraduação em Educação. Porto Alegre: UFRGS, 2000.

CARVALHO, I. C. de M. Educação Ambiental: a formação do sujeito ecológico. 6. ed. São Paulo: Cortez Editora, 2016.

CASTRO, E. Introdução a Foucault. Belo Horizonte: Autêntica Editora, 2014.

DREYFUS, H.; RABINOW, P. Michel Foucault: uma trajetória filosófica: para além do estruturalismo e da hermenêutica. 2. ed. Rio de Janeiro: Forense Universitária, 2013.

FOUCAULT, M. As palavras e as coisas. 9. ed. São Paulo: Martins Fontes, 2007.

FOUCAULT, M. Nascimento da biopolítica. Lisboa: Edições 70, 2010.

FOUCAULT, M. Vigiar e punir: nascimento da prisão. 41. ed. Petrópolis, Rio de Janeiro: Vozes, 2013a.

FOUCAULT, M. A arqueologia do saber. 8. ed. Rio de Janeiro: Forense Universitária, 2013b.

FOUCAULT, M. As Técnicas de Si. In: FOUCAULT, Michel. Ditos e escritos, v. IX: genealogia da ética, subjetividade e sexualidade. (Organizado por Manoel Barros da Motta). Rio de Janeiro: Forense Universitária, 2014a.

FOUCAULT, M. História da sexualidade 2: o uso dos prazeres. São Paulo, Paz e Terra, 2014b.

FOUCAULT, M. Ditos e escritos, vol. IX: genealogia da ética, subjetividade e sexualidade. Rio de Janeiro: Forense Universitária, 2014c.

GONÇALVES, C. W. P. Os (des)caminhos do meio ambiente. 14. ed. São Paulo: Contexto, 2008.

revista brasileira educação ambiental 
GUATTARI, F. As três ecologias. Campinas, São Paulo: Papirus, 2009.

GUATTARI, F. Caosmose: um novo paradigma estético. São Paulo: Editora 34, 2012.

INOCÊNCIO, A. F. Derivas da ecogovernamentalidade: a construção de territórios existenciais por meio das tecnologias de si. $152 \mathrm{f}$. Tese (Doutorado em Ensino de Ciências e Educação Matemática) - Universidade Estadual de Londrina. Programa de Pós-Graduação em Ensino de Ciências e Educação Matemática. Londrina, 2019.

INOCÊNCIO, A. F; SALVI, R. F. Escavando saberes: a análise arqueológica como estratégia para uma Educação Ambiental pós-moderna. Revista Brasileira De Educação Ambiental (RevBEA), São Paulo, v. 12, n. 4, p. 165179, 2017.

MAKNAMARA, M. Educação Ambiental e Nordestinidade: desafios à práxis ecologista. Revista Brasileira De Educação Ambiental (RevBEA), São Paulo, v. 9, n. 2, p. 10-17, 2013.

MALETTE, S. Foucault para o próximo século: ecogovernamentalidade. Ecopolítica, São Paulo, v. 1, p. 4-25, 2011.

MELO E SOUZA, R. Qual sujeito, qual ecologia? O sujeito ecológico e as posturas ideológicas do movimento ambientalista brasileiro. Revista Brasileira de Educação Ambiental (Revbea), São Paulo, v. 9, n. 2, p. 214-224, 2014.

PASSETTI, E. Ecopolítica: procedências e emergência. In: CASTELO BRANCO, G.; VEIGA-NETO, A. (orgs.). Foucault: filosofia \& política. Belo Horizonte: Autêntica Editora, 2013.

RODRIGUES, T. Segurança planetária, entre o climático e o humano. Ecopolítica, São Paulo, v. 3, p. 5-41, 2012.

PELBART, P. P. O avesso do niilismo: cartografias do esgotamento. 2. ed. São Paulo: $n-1$ edições, 2016.

ROLNIK, S. Esferas da insurreição: notas para uma vida não cafetinada. São Paulo: N-1 Edições, 2018.

SAMPAIO. P. I. M. de. Indivíduo: começo, meio e fim do neoliberalismo. in. RAGO, M.; PELEGRINI, M. (orgs.). Neoliberalismo, feminismos e contracondutas: perspectivas foucaultianas. São Paulo: Intermeios, 2019.

SILVA, P. O.; VIEIRA, V. T.; HENNING, P. C. Educação Ambiental e discursos midiáticos: gerenciando modos de vida contemporâneos. IX ANPED Sul: Seminário de Pesquisa em Educação da Região Sul, 2012. Disponível em: $<$ http://www.ucs.br/etc/conferencias/index.php/anpedsul/9anpedsul/\%0Bpaper/v iewFile/2255/839>. Acesso em: 08 abr. 2020. 